\title{
"Dirty nanostructures": aerosol-assisted synthesis of temperature stable mesoporous metal oxide semiconductor spheres comprising hierarchically assembled zinc oxide nanocrystals controlled via impurities
}

\begin{abstract}
Daniela Lehr, ${ }^{a}$ Dennis Großmann, ${ }^{\mathrm{b}}$ Wolfgang Grünert ${ }^{\mathrm{b}}$ and Sebastian Polarz ${ }^{\star a}$
Structural disintegration or the loss of accessible surfaces of functional nanostructures due to processes involving mass transport (e.g. sintering) is a serious problem for any application of these materials at elevated temperatures, like in heterogeneous catalysis or chemical sensing. Phases with low sintering temperatures, e.g. some metals or metal oxides like zinc oxide $(\mathrm{ZnO})$, are very sensitive in this respect. Therefore, it is not only relevant to prepare important materials with refined morphologies, but the desired features need to be stable under real conditions. In this study, we describe the preparation of mesoporous $\mathrm{ZnO}$ nano-/microspheres by means of a template-assisted aerosol technique. Furthermore, by intentional introduction of impurity elements as dopants, specific surface areas and porosities of the prepared materials can be increased significantly. The impurities also strongly improve the thermal stability of the described $\mathrm{ZnO}$ nanostructures against thermal sintering. Although the pure $\mathrm{ZnO}$ material suffers from a complete loss of porosity, the structures of the impure ("dirty") materials change only negligibly. Even at $500{ }^{\circ} \mathrm{C}$ morphology and porosity are preserved. The latter advantageous property was used for testing the novel nanocatalysts in heterogeneous catalysis.
\end{abstract}

\section{Introduction}

Semiconducting metal oxide materials that exhibit porosity and high surface area are of major importance for a large number of applications. Contemporary examples are, for instance, photocatalysis, in particular the water splitting reaction ${ }^{\mathbf{1 , 2}}$ or supercapacitive energy storage. ${ }^{3}$ It is, however, also important to note that for more than one century many nanoporous metal oxides have been crucial components of materials used in heterogeneous catalysis. ${ }^{4}$ The catalytic hydrogenation of $\mathrm{CO} / \mathrm{CO}_{2}$ to methanol is a representative case..$^{5,6}$ There is much interest in

${ }^{a}$ University of Konstanz, Dept of Chemistry, Universitaetsstr. 10, 78457 Konstanz, Germany. E mail: sebastian.polarz@uni konstanz.de; Fax: +497531 884406; Tel: +497531884415

${ }^{b}$ Ruhr University Bochum, Dept of Chemistry, Universitaetsstr. 150, 44801 Bochum, Germany the latter reaction, because methanol has been discussed intensively as a convenient molecule for energy storage, respectively, for applications related to fuel cells. ${ }^{79}$ The industrial catalyst for methanol synthesis is composed of zinc oxide (ZnO) nanoparticles aggregated into a porous network, which hosts a significant amount of metallic copper crystallites with a size of $\approx 10 \mathrm{~nm} . .^{10,11}$ The catalysts contain $\mathrm{Al}_{2} \mathrm{O}_{3}$ on the order of $10-15 \mathrm{wt} \%$, which is considered as a structural promoter. ${ }^{12}$ The $\mathrm{Cu} / \mathrm{ZnO} / \mathrm{Al}_{2} \mathrm{O}_{3}$ composite is a relatively complex system, because it shows the so-called strong-metal support interaction (SMSI) effect. ${ }^{11,13}$ Although the industrial catalyst is prepared via a coprecipitation method, it is still an open question whether more refined nanoarchitectures could lead to beneficial effects in catalysis. ${ }^{14}$ Zinc oxide is also involved in other important processes of heterogeneous catalysis. $\mathrm{Au} / \mathrm{ZnO}$ materials are widely used for water-gas shift reaction and gas sensing. ${ }^{15,16} \mathrm{Ag} /$ ZnO materials have shown promising properties in photocatalysis due to enhanced charge separation. ${ }^{17}$

$\mathrm{ZnO}$ is unique because it offers a multitude of functional properties and applications together with high availability, low price, and non-toxicity. It belongs to the class of wide-gap semiconductors with a direct band gap of $3.37 \mathrm{eV} .{ }^{18}$ Apart from its use in catalysis discussed above, its semiconducting properties combined with a large exciton binding energy allow for applications in the field of electronics and optoelectronics ${ }^{19}$ for 
instance as varistors,${ }^{20}$ light-emitting devices, ${ }^{21}$ thin-film transistors $^{22}$ or gas sensors. ${ }^{23}{ }^{25} \mathrm{ZnO}$ is also very well suited for application in environmental remediation. Because of its good catalytic properties, $\mathrm{ZnO}$ is able to remove toxic heavy metal ions via photoreduction under UV-light irradiation. ${ }^{26,27}$ Some reports demonstrated very good capacities for adsorption of $\mathrm{Cr}(\mathrm{VI}), \mathrm{Cu}(\mathrm{II})$ or $\mathrm{Pb}(\mathrm{II})$ ions from aqueous solution. ${ }^{28}{ }^{30}$ Thus, $\mathrm{ZnO}$ nanostructures have been in the focus of growing interest in research and industries worldwide. ${ }^{31,32}$

Despite their large surface to volume ratio, classic nanoparticles are not suitable for many applications because they are either not separable from solution (if properly stabilized) or tend to form irregular and colloidal unstable aggregates (if not stabilized)..$^{33}$ Therefore, hierarchically structured, highly porous aggregates with spherical shape constructed of nanoscaled $\mathrm{ZnO}$ building blocks are of major interest, because they combine both the advantages of nanosized particles as well as of microstructures, and at the same time they possess semiconductor features with enhanced light-harvesting capability. It is also worth noting that spherical nanomaterials of other metal oxides are of major interest, like $\mathrm{TiO}_{2}$ materials prepared via gas-phase methods. ${ }^{34}{ }^{36}$ Porous $\mathrm{ZnO}$ spheres find application in DSSCs, ${ }^{37,38}$ gas sensing, ${ }^{39}$ photocatalysis,${ }^{40,41}$ and as adsorbents ${ }^{28}$ in environmental remediation. Although it is quite easy to shape $\mathrm{ZnO},{ }^{31,32,42}$ one of the main disadvantages is correlated with the high tendency of zinc oxide for sintering at relatively low temperatures, in particular in the presence of humidity. As a result, one can observe quite often that an initial $\mathrm{ZnO}$ nanostructure disintegrates quickly during a certain application. Thus, the stabilization of a particular, nanostructured state and retention of the high surface area at the same time remains an important challenge in zinc oxide research.

In the current manuscript, it is also important to discuss how properties of $\mathrm{ZnO}$ are affected by the presence of heteroelements (E). Potential reaction pathways leading to alternative phases with defined composition are not considered here. Electronic and optical properties of $\mathrm{ZnO}$ can be controlled by specific anion or cation substitution in the sub-lattice, hereafter abbreviated as E@ZnO. ${ }^{43} \mathrm{~N}$-doped $\mathrm{ZnO}$ materials, obtained by incorporation of $\mathrm{F}^{-}$(instead of $\mathrm{O}^{2-}$ ) or $\mathrm{Al}^{3+}$ (instead of $\mathrm{Zn}^{2+}$ ), possess an enhanced conductivity and are intensively discussed as promising transparent conducting oxides (TCOs). ${ }^{44} 48$ The size of the optical gap can be modified by iso-valence substitution. Whereas the incorporation of $\mathrm{Mg}^{2+}$ results in an enlargement of the band gap, ${ }^{49}$ we were able to show recently that the substitution of oxygen by sulfur leads to a reduction of gap energy, and consequently to enhanced light absorption ability in the visible spectral range. ${ }^{50,51}$ It is interesting to note that there is relatively limited attention regarding the effect of electronic doping of the semiconductor concerning the catalytic properties of E@ZnO/metal heterostructures. ${ }^{52}$

Herein, we describe the synthesis of nanosized zinc oxide spheres possessing additional mesoporosity. Intentional impurities $(\mathrm{S}, \mathrm{Al})$ are introduced using a template assisted aerosol method. The effect of those impurities on the particle structure and porosity is analyzed. Furthermore, we will investigate the capability of the resulting materials for adsorption of heavy metal ions from solution. $\mathrm{Cu}^{2+}$ has been selected, because the resulting materials can be directly converted to catalysts relevant for methanol synthesis. ${ }^{14,53,54}$

\section{Results and discussion}

\section{Hierarchically structured porous E@ZnO spheres}

For the synthesis of mesoporous spheres we adopted a method presented by Brinker et al. for the generation of spherical mesoporous silica $\left(\mathrm{SiO}_{2}\right)$ nanoparticles (see Scheme 1). ${ }^{55,56}$ Several modifications were made. It is self-evident that alternative precursors are required, which are suitable for the delivery of the desired elements (Zn, Al, S). The liquid methylzinc methoxyethoxide tetramer with heterocubane structure $\left([\mathrm{MeZnOEtOMe}]_{4}\right)(\mathbf{1})$ was used as a single-source precursor for $\mathrm{ZnO}{ }^{14,24,25,57}{ }^{65}$ It is known that this compound provides $\mathrm{ZnO}$ either via thermal decomposition, ${ }^{25,63}{ }^{66}$ or using sol-gel methodology (hydrolysis and polycondensation). ${ }^{57,58,60,61,67}$

The precursors used for the introduction of $\mathrm{E}=\mathrm{S}$ or $\mathrm{Al}$ should preferably pursue similar (thermal) reaction pathways in the gas-phase. Thus, we have selected $\left[\mathrm{MeZnS}{ }^{\text {iso }} \mathrm{Pr}\right]_{8}(2),{ }^{51}$ respectively $\mathrm{Al}\left(\mathrm{O}^{\text {iso }} \mathrm{Pr}\right)_{3}$ (3) as molecular sources due to their chemical similarity to the $\mathrm{ZnO}$ precursor. Since the latter compounds are sensitive against water, the entire process has to be conducted under strict exclusion of humidity, which is another, major difference to the method presented by Brinker for silica. Toluene was selected as the solvent, because all compounds are well soluble in it and it evaporates without decomposition even at high temperatures as applied here. The $\mathrm{Zn}$ : E ratio in the final product can be controlled via addition of a designated amount of (2) or (3) to this precursor solution. Furthermore, an auxiliary is added to the precursor solution, e.g. an amphiphilic compound, which is able to generate open porosity via a templating mechanism. ${ }^{68}$ The described mixture is atomized leading to an aerosol of liquid, polydisperse droplets in a stream of nitrogen (Scheme 1). The aerosol is passed through a gas-phase reactor. Here, the solution becomes concentrated due to evaporation of the solvent. Up to this point (zone I), there should be no conversion of the precursors into the inorganic phases, because the aerosol droplets do not get hot enough. Once all toluene has evaporated, the thermal reaction of the precursor(s) takes place (zone II). Ensuing from a

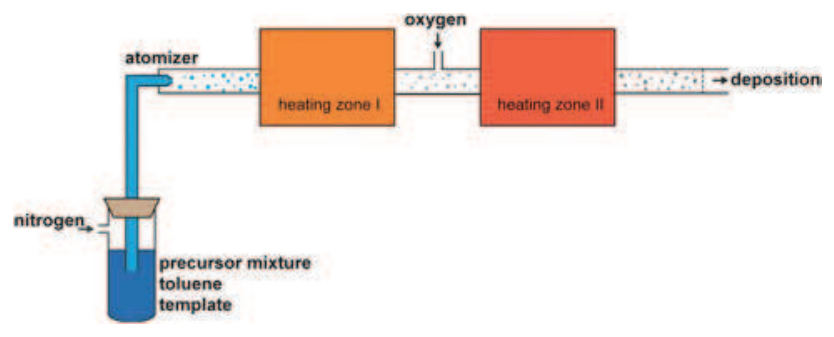

Scheme 1 Set-up for the aerosol synthesis of mesoporous $\mathrm{ZnO}$ spheres. The precursor solution is atomized in a nitrogen flow and passed into a tube oven (heating zone $1,150{ }^{\circ} \mathrm{C}$ ) where the solvent evaporates. After oxygen addition the aerosol is passed into a second tube furnace (heating zone II, 350 $0^{\circ}$. 
homogeneous distribution of the precursors, one can expect that the impurity atoms become entrapped in the $\mathrm{ZnO}$ matrix.

Samples composed of pure $\mathrm{ZnO}$ were synthesized as reference materials first, using a precursor solution containing only compound (1) and the surfactant Brij 58 as a structure-directing agent. ${ }^{69}$ The product obtained directly after the aerosol process was investigated by a combination of analytical techniques. The scanning electron microscopy (SEM) micrograph shown in the ESI (ESI- $1 \dagger$ ) shows that a polydisperse ensemble of spherical nanoparticles with diameters between $\approx 20 \mathrm{~nm}$ and $1 \mu \mathrm{m}$ has been obtained. The significant polydispersity of the particle size is typical for aerosol methods since the particles retain the size distribution of the previous droplets. The surface of the nanoparticles looks smooth and no particular internal structure could be observed using transmission electron microscopy (TEM) (see micrograph in Fig. 1a). Selected area electron diffraction (SAED) indicates the absence of any diffraction signals. Thus, one can conclude that the particles obtained directly after the aerosol process are almost amorphous. The latter hypothesis is supported by powder X-ray diffraction (PXRD) (given in ESI-1†). Only very broad diffraction signals are present indicating a particle size of smaller than $2 \mathrm{~nm}$. Due to the remaining template, no porosity can be observed at this stage (Fig. 2a; Scheme 2a). Thermogravimetric analysis (TGA) proves that the particles still contain significant amounts of volatile residues (see ESI-1 $\dagger$ ). There are two distinct mass loss $(\Delta m)$ steps. $\Delta m=15 \%$ in the temperature range $25-130{ }^{\circ} \mathrm{C}$ can be attributed to the removal of the remaining solvent and organic residues from the precursor. The template $(\Delta m=22 \%)$ is removed at higher temperatures $\left(T_{\max }=274{ }^{\circ} \mathrm{C}\right)$.
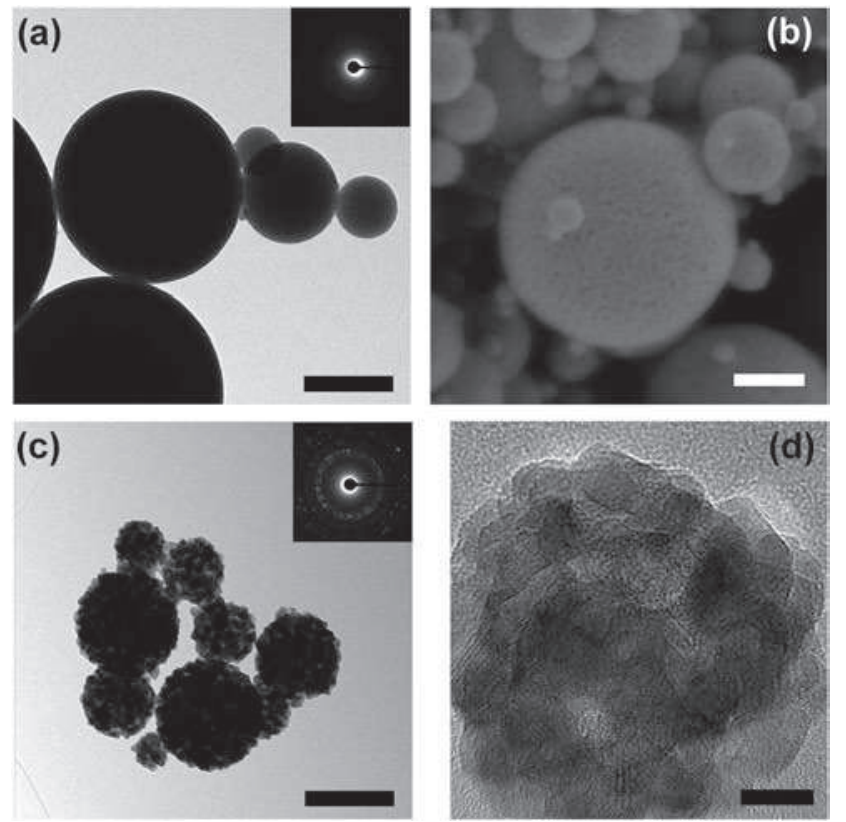

Fig. 1 TEM and SAED of the product obtained via the aerosol-assisted process using compound (1) as a precursor, (a) state prior to calcination (scale bar $200 \mathrm{~nm}$ ). (b d) ZnO nano-/microspheres after calcination, SEM (b; scale bar 200 nm), TEM and SAED (c; scale bar $200 \mathrm{~nm}$ ) and HRTEM micrograph (d; scale bar $10 \mathrm{~nm}$ ).
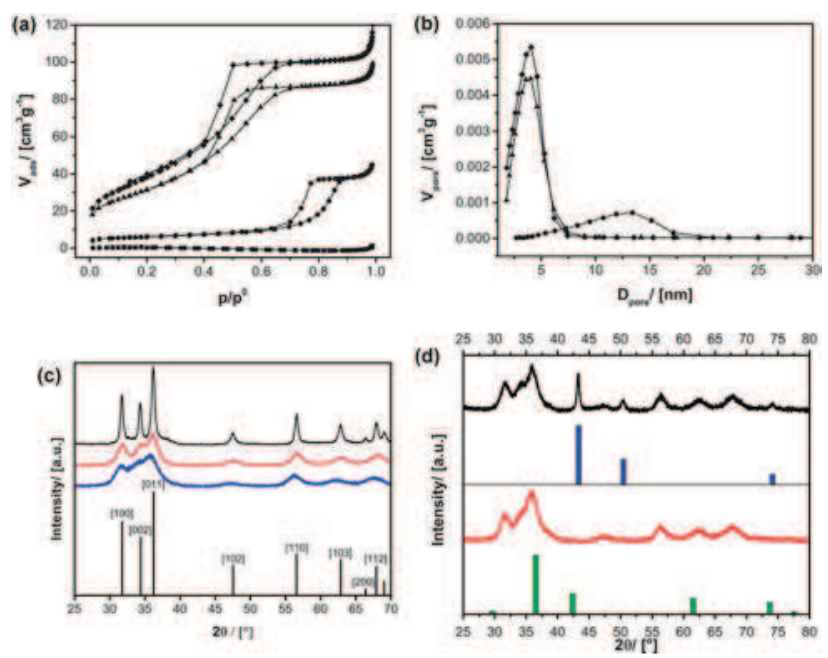

Fig. 2 (a) $\mathrm{N}_{2}$ physisorption isotherms (adsorption and desorption) of the non-porous spheres prior to calcination (squares), the $\mathrm{ZnO}$ spheres obtained after calcination (circles), the Al@ZnO material (triangles) and the S@ZnO material (hashes). (b) BJH pore-size distribution functions. (c) PXRD patterns of the pure $\mathrm{ZnO}$ (black graph), the Al@ZnO (red graph) and the S@ZnO materials (blue graph). The pattern of bulk $\mathrm{ZnO}$ (black bars) is also shown as a reference. (d) PXRD patterns of the mesoporous SaZnO material after $\mathrm{Cu}^{2+}$ infiltration and drying at $300{ }^{\circ} \mathrm{C}$ (red graph) and after reduction at $240{ }^{\circ} \mathrm{C}$ (black graph). The reference patterns of $\mathrm{Cu}_{2} \mathrm{O}$ (green bars; ICDD: 01-073-6371) and of elemental $\mathrm{Cu}$ (blue bars; ICDD: 01-085-1326).

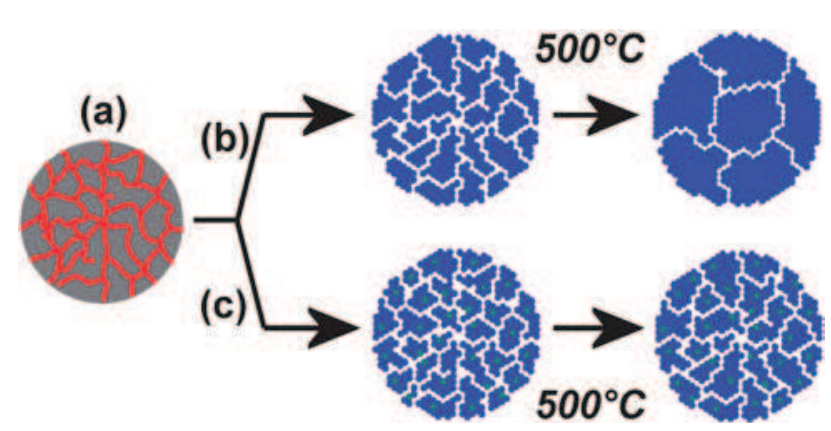

Scheme 2 (a) Amorphous spheres obtained directly after aerosol assisted synthesis; the material still contains the template (red color). Template removal via calcination for the pure $\mathrm{ZnO}$ material (b) and the EaZnO material (c). ZnO blue; impurity atoms green dots. The effect of sintering is also indicated for both materials.

The removal of the template can be achieved via calcination at $300{ }^{\circ} \mathrm{C}$ (see Experimental part; Scheme 2b). Electron microscopy investigation of the resulting material shows that the spherical morphology of the nanoparticles has been maintained (Fig. 1b). However, the roughness of the surfaces seen in SEM is a first indication for the porosity of the particles. Nitrogen physisorption analysis confirms the latter assumption (Fig. 2a). The isotherm, IUPAC type IV ${ }^{70}$ is characteristic for a mesoporous material. The Barrett-Joyner-Halenda (BJH) pore size distribution function (PSD) was calculated (Fig. 2b). ${ }^{71}$ The PSD is relatively broad and exhibits a maximum at a pore diameter $D_{\text {pore }}$ of $13 \mathrm{~nm}$. This is much larger than expected if the pore size would have been determined solely by the Brij58 
template $\left(D_{\text {pore }}(\exp ) \approx 4 \mathrm{~nm}\right) .{ }^{69}$ The specific surface area $\left(A_{\mathrm{sp}}\right)$ calculated using the Brunauer-Emmett-Teller (BET) ${ }^{72}$ method is about $60.5 \mathrm{~m}^{2} \mathrm{~g}^{-1}$, which is a reasonable value for porous ZnO. ${ }^{24,25,62,73}$ TEM and HRTEM micrographs shown in Fig. 1c and d reveal that the spherical particles consist of many crystallites in the $10 \mathrm{~nm}$ size range. Crystallite sizes $D_{\text {cryst }}$ have also been obtained from the evaluation of the PXRD peak broadening (Fig. 2c) using the Scherrer equation. ${ }^{74}$ The evaluation of the [100] peak results in $D_{\text {cryst }}=8.6 \mathrm{~nm}$, in good agreement with the value from TEM. It becomes evident, however, that the strong tendency of $\mathrm{ZnO}$ for crystallization even at such low temperatures as $300{ }^{\circ} \mathrm{C}$ annihilates any structure directing effect of the organic template. There is still some porosity, but this is due to the imperfect, non-dense packing of the randomly oriented ZnO nanoparticles (see Fig. 1c).

The synthesis of the materials containing either $\mathrm{S}$ or $\mathrm{Al}$ as an impurity has been conducted under identical conditions except for the composition of the two precursors (1) + (2) or (1) + (3) used for aerosol synthesis. From PXRD it can be concluded that the presence of the impurity atoms has a pronounced influence on crystallinity (Fig. 2c). The crystallites in the Al-containing $\mathrm{ZnO}$ (Al@ZnO) are only $4.2 \mathrm{~nm}$ large, and $D_{\text {cryst }}$ is even smaller $(3.0 \mathrm{~nm})$ in the case of S@ZnO. The reduction of the crystallite size has significant consequences for the porosity of the materials. The $\mathrm{N}_{2}$ physisorption isotherms remain type IV, but the capillary condensation step is shifted to lower relative pressure (Fig. 2a). This is due to smaller pores, which are also documented in the BJH pore-size distribution functions (Fig. 2b; $\left.D_{\text {pore }}(\mathrm{Al} @ Z \mathrm{ZnO})=3.9 \mathrm{~nm} ; D_{\text {pore }}(\mathrm{S} @ Z \mathrm{ZnO})=3.3 \mathrm{~nm}\right)$. Both materials exhibit a pore-size similar to silica materials prepared using Brij 58, and this documents the successful application of the template. ${ }^{69}$ The specific surface area is $115 \mathrm{~m}^{2} \mathrm{~g}^{-1}$ for Al@ZnO and $131 \mathrm{~m}^{2} \mathrm{~g}^{-1}$ for S@ZnO. The mesoporous structure as well as the nanocrystalline nature of the nano-/microspheres are documented by TEM micrographs shown in Fig. 3 .

Unlike mesoporous silica materials prepared via liquid-crystal templates, the pore-system of the mesoporous $\mathrm{ZnO}$ materials is not highly ordered. ${ }^{55,56}$ This is not surprising, because one needs to consider that the non-aqueous environment described here hampers the efficient structuring of the amphiphiles. Nevertheless, the pore size can be varied to a certain extent by using surfactants with different chain lengths (see also ESI- $2 \dagger$ ). Using the Pluronic triblock copolymers, a pore-size of $D_{\text {pore }}(\mathrm{Al} @ \mathrm{ZnO})=$ 5.3 was achieved for P123 and $D_{\text {pore }}(\mathrm{Al} @ Z n O)=7.9$ for F127; see ESI-2. $\dagger$

Evidence for the successful incorporation of S or Al into the mesoporous ZnO matrix is supplied by selected area energy dispersive X-ray spectroscopy (SA-EDX) (data given in ESI-3†). The concentration of the doping element is 6.2\% for Al@ZnO and 9.5\% for S@ZnO. Together with the PXRD data (Fig. 2c), which show that there is no separation into $\mathrm{ZnO}$ and a second phase e.g. $\mathrm{Al}_{2} \mathrm{O}_{3}$, it suggests that the heteroelements $(\mathrm{Al} / \mathrm{S})$ have substituted zinc and oxygen in the crystal lattice, respectively. For further clarification of the chemical state of the impurity atoms, X-ray photoelectron spectroscopy (XPS) was performed (data shown in ESI-3†). Characterization of the sample using XPS is difficult due to the relatively low amount of aluminum
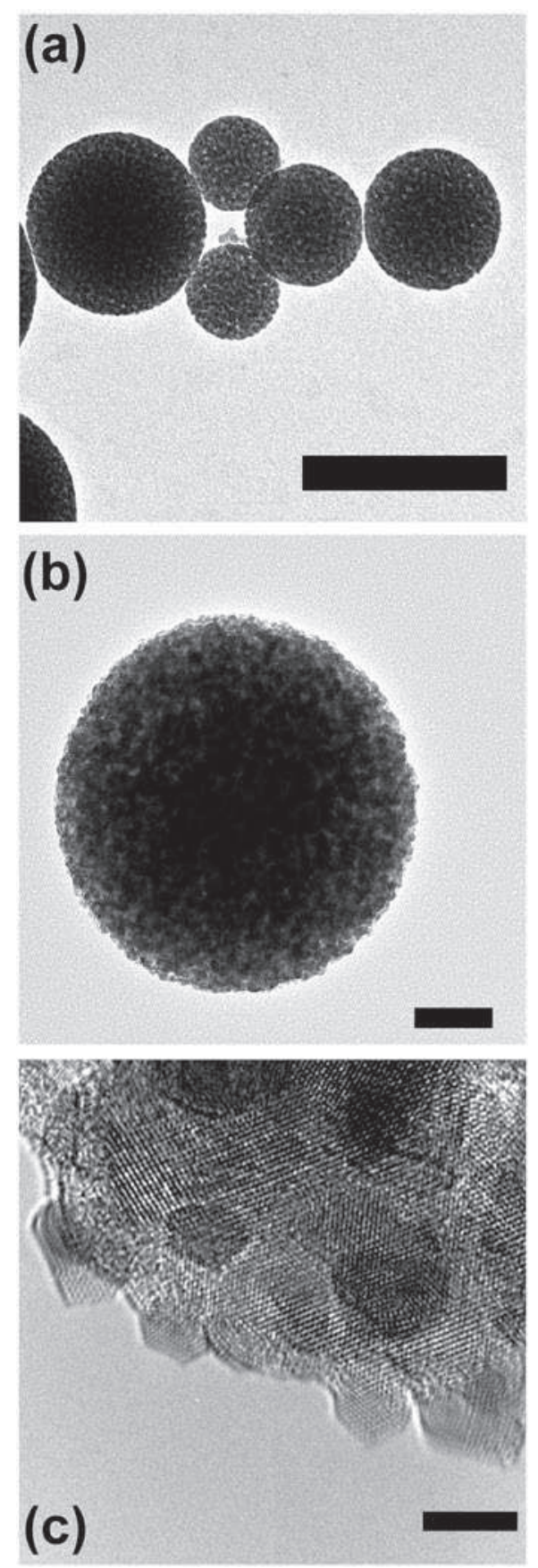

Fig. 3 (a) TEM micrograph of the spherical, mesoporous $\mathrm{ZnO}$ particles containing sulfur as an impurity; scale bar $200 \mathrm{~nm}$. TEM (b; scale bar 50 $\mathrm{nm}$ ) and HRTEM (c; scale bar $5 \mathrm{~nm}$ ) micrographs of the of the spherical, mesoporous $\mathrm{ZnO}$ particles containing aluminum as an impurity.

and the superposition with low-energy X-ray satellites of the $\mathrm{Zn}_{3 \mathrm{p}}$ photoelectron peak $(80 \mathrm{eV}) .{ }^{75}$ However, the signal at $74.5 \mathrm{eV}$ can clearly be assigned to $\mathrm{Al}^{3+}$. Because the current XPS data contain only limited information, ${ }^{27} \mathrm{Al}$ solid-state NMR measurements were performed as well. The comparison of the ${ }^{27} \mathrm{Al}-\mathrm{NMR}$ spectrum to data published in the literature reveals that like for other Al-containing $\mathrm{ZnO}$ materials there are different types of $\mathrm{Al}^{3+}$ centers present. ${ }^{76}$ The signal at $\delta=$ $82 \mathrm{ppm}$ can be assigned to aluminum on zinc lattice positions; 
$\mathrm{Al}_{\mathrm{Zn}}$ in Kröger-Vink notation. A broad signal at $\delta=70 \mathrm{ppm}$ originates from $\mathrm{Al}^{\mathrm{III}}$ in a much less defined environment but still with four-fold coordination, presumably on interstitial positions $\left(\mathrm{Al}_{\mathrm{i}}\right)$. Minor amounts of $\mathrm{Al}$ with six-fold coordination can also be seen $(\delta=14 \mathrm{ppm})$.

Since the ionic radius of $\mathrm{S}^{2-}(r=184 \mathrm{pm})$ is much larger than that of $\mathrm{O}^{2-}(r=140 \mathrm{pm})$, oxygen substitution leads to lattice expansion which results in a shift of signal positions towards lower angles in PXRD for the S@ZnO material. ${ }^{51}$ The successful incorporation of the heteroelements is the key requirement for enhancing the stability of the $\mathrm{ZnO}$ nanostructures at elevated temperatures. We treated the undoped $\mathrm{ZnO}$ and the E@ZnO sample at different temperatures $(T=300-500)$ for $10 \mathrm{~h}$ and monitored the development of crystallite size and specific surface area using PXRD and $\mathrm{N}_{2}$ physisorption analysis. The resulting relationship is shown in Fig. 4.

It can be seen that there is a strong growth of the pure $\mathrm{ZnO}$ crystallites due to sintering when the temperature is raised. At the same time the pore diameter increases significantly (data given in ESI-4 $\dagger$ ) and the specific surface area drops (Fig. 4b). In contrast to this, the crystal size remains nearly constant for Al@ZnO (Fig. 4a), the pore-size and also the surface area are affected much less. Similar findings were made for the S@ZnO materials. Although porosity vanishes quickly for pure $\mathrm{ZnO}$ materials, the Al@ZnO sample is much more stable (see also Scheme 2). Finally, after annealing at $500{ }^{\circ} \mathrm{C}$ the morphology of both materials was investigated using TEM (Fig. 5). It can be seen that the nanostructure of Al@ZnO is still intact (Fig. 5a). However, the morphology of the pure $\mathrm{ZnO}$ materials has changed significantly (Fig. 5b). The size of the individual crystals has become so large, that hardly any feature of the original structure is left (Scheme 2).

The effects of the impurity atoms can be understood by considering analogues from the macroscopic world, respectively, ceramics. It is well known that the thermal stability of silica glass can be improved by heteroelements, for instance boron substituting silicon. It is assumed that the substitution leads to a local disturbance of the structure and lattice strain. This leads to an additional activation barrier for reconstructions and mass transport. ${ }^{77}$ Key properties like the glass transition temperature are influenced by the mentioned point defects. Obviously, similar effects can also play a major role in nanostructures regarding particle size and sintering stability. ${ }^{78,79}$
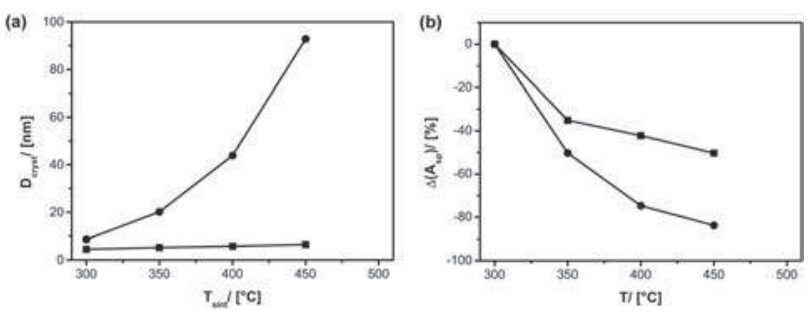

Fig. 4 Correlation of the $\mathrm{ZnO}$ crystallite size (a) and the difference in specific surface area (b) as a function of sintering temperature. Pure $\mathrm{ZnO}$ materials (circles) and AlaZnO (squares).
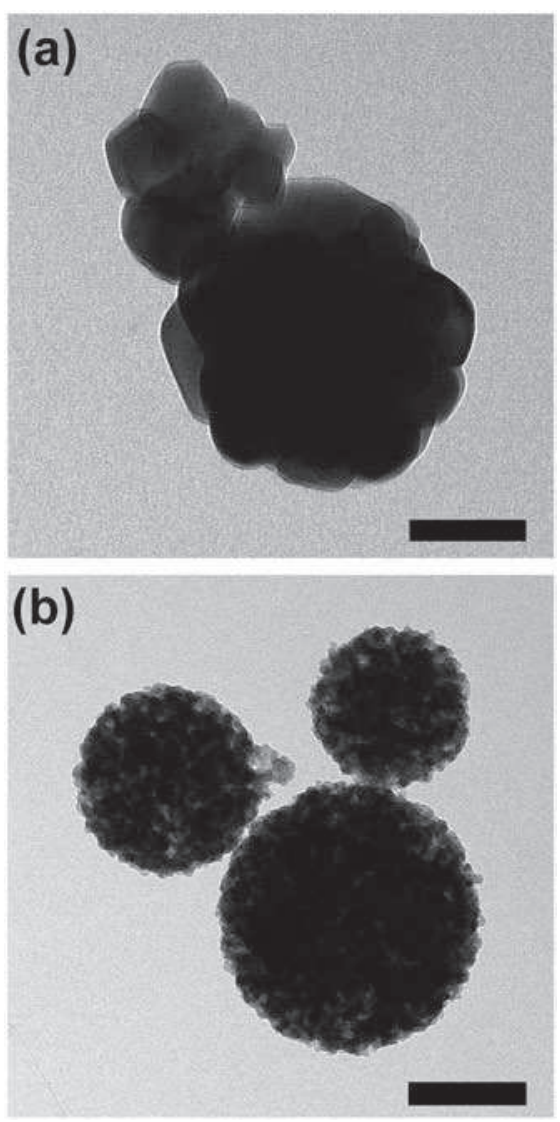

Fig. 5 TEM micrographs of pure $\mathrm{ZnO}$ materials (a) and Al@ZnO materials (b) after high-temperature treatment $\left(500^{\circ} \mathrm{C}\right)$ for $10 \mathrm{~h}$. Scale bar $100 \mathrm{~nm}$.

\section{Cu@ZnO composites for heterogeneous catalysis}

Porous $\mathrm{ZnO}$ materials with a high specific surface area are well suited to adsorb heavy metal ions from wastewater. The idea of binding undesired metal ions and converting these samples into useful nanocomposite materials is a promising approach. ${ }^{30}$ $\mathrm{Cu}^{\mathrm{II}}$ was chosen because of the obvious connection to methanol synthesis. First, the maximum uptake capacity for $\mathrm{Cu}^{\mathrm{II}}$ was determined. The porous spheres prepared using the aerosol method (see above) were dispersed in an aqueous $\mathrm{Cu}\left(\mathrm{NO}_{3}\right)_{2}$ solution. After centrifugation, the concentration of residual $\mathrm{Cu}^{\mathrm{II}}$ remaining in solution was determined using atomic absorption spectroscopy. It could be proven that all mesoporous $\mathrm{ZnO}$ spheres exhibit extraordinarily high values for the removal capacity $\left(1000 \mathrm{mg}_{\mathrm{Cu}} \mathrm{g}_{\mathrm{ZnO}}{ }^{-1}, 897 \mathrm{mg}_{\mathrm{Cu}} \mathrm{g}_{\mathrm{S} @ Z \mathrm{ZnO}^{-1}}\right.$ and $948 \mathrm{mg}_{\mathrm{Cu}}$ $\left.\mathrm{g}_{\mathrm{Al} @ Z n \mathrm{Zn}^{-1}}\right)$. It becomes evident that the copper adsorption capacity does not correlate directly with the specific surface area of the related materials (see above). This indicates that not only the surface area but also the chemical state of the surface is an important factor. We assume that the incorporation of $\mathrm{Al}^{3+}$ instead of $\mathrm{Zn}^{2+}$ or sulphur instead of oxygen reduces the density of negative charge on the surfaces, and this reduces the interaction with the copper cations.

For catalysis a second set of samples was prepared, characterized by a lower $\mathrm{Zn}$ : $\mathrm{Cu}$ ratio of $4: 1$ (see Experimental part). 
After infiltration, the samples were dried at $300{ }^{\circ} \mathrm{C}$. STEM-EDX elemental mapping was performed for visualizing the distribution of copper and zinc ions (data given in ESI-6†). The homogeneous distribution of both elements, $\mathrm{Zn}$ and $\mathrm{Cu}$, throughout the particle is obvious. Furthermore, STEM-EDX line scan analysis of a single sphere reveals that copper $\mathrm{Cu}^{\mathrm{II}}$ has entered the interior pore space of the particles and is homogeneously distributed, because the signal intensity clearly increases towards the center of the sphere (Fig. 6, ESI-7 $\dagger$ ). The products were also analysed using PXRD (Fig. 2d, ESI-5 $\dagger$ ). The obtained pattern is almost identical to the pattern of nanocrystalline E@ZnO prior to $\mathrm{Cu}^{2+}$ infiltration. It can be concluded that the mesoporous matrix has effectively suppressed the growth of a secondary phase like $\mathrm{CuO}_{2}$ or $\mathrm{CuO}$ confined to the pores. ${ }^{14}$ Furthermore, the aqueous infiltration process has not induced any restructuring of the $\mathrm{ZnO}$ matrix.

The $\mathrm{Cu}^{\mathrm{II}}$ containing mesoporous $\mathrm{ZnO}$ particles represent promising candidates for application as a methanol synthesis catalyst. The copper loaded E@ZnO spheres were reduced at $513 \mathrm{~K}$ in dilute $\mathrm{H}_{2}$. As expected, reduction of copper and formation of $\mathrm{Cu}^{0}$ nanoparticles take place, as proven by PXRD (Fig. 2d; ESI-5 $\dagger$ ). The diffraction signals of elemental copper are clearly visible, which confirms the successful conversion into a semiconductor-metal nanocomposite. From the line width, an average size of $24 \mathrm{~nm}$ can be deduced for the $\mathrm{Cu}$ particles. It is worth mentioning that also under catalytic conditions there is no narrowing of the ZnO signals. The E@ZnO matrix is still stable. As expected, the presence of $\mathrm{Cu}$ has some influence on the porosity of the samples (isotherms shown in ESI-8 $\dagger$ ). However, the pores are still accessible and significant surface area is present $\left(52.8 \mathrm{~m}^{2} \mathrm{~g}^{-1}\right.$ for $\mathrm{S} @ \mathrm{ZnO} / \mathrm{Cu}$ and $60.6 \mathrm{~m}^{2} \mathrm{~g}^{-1}$ for $\mathrm{Al} @ \mathrm{ZnO} / \mathrm{Cu})$.

The Cu ${ }^{\text {II }}$ containing E@ZnO spheres were tested in methanol synthesis. After in situ reduction with diluted $\mathrm{H}_{2}(2 \%$ in $\mathrm{He})$ at $513 \mathrm{~K}$, synthesis gas was passed over the catalyst and the

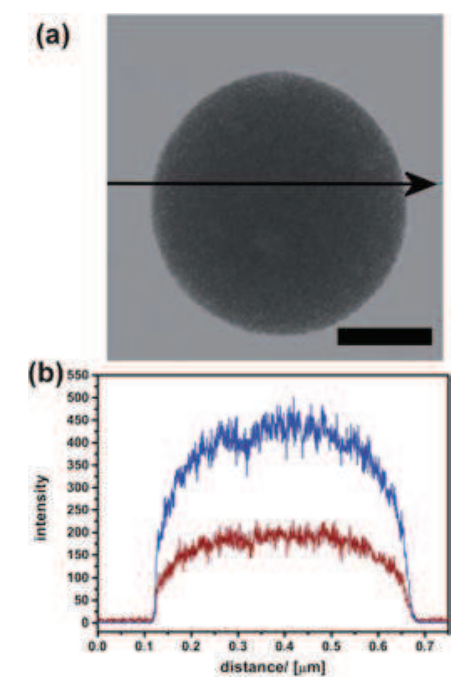

Fig. 6 (a) Scanning TEM results for one AlaZnO mesoporous sphere after infiltration of Cu"; scale bar $200 \mathrm{~nm}$. The arrow indicates the trace for the EDX line scan. (b) Results of the EXD line-scan measurement (blue graph $\mathrm{Zn}_{\kappa \alpha} ;$ black graph $\mathrm{Cu}_{\kappa \alpha}$ ). methanol concentration was measured at 8 bar and $493 \mathrm{~K}$ (Fig. 7) using a detector based on IR photometry.

It can be seen that methanol was formed over both the $\mathrm{Al} @ \mathrm{ZnO} / \mathrm{Cu}$ and the $\mathrm{S} @ \mathrm{ZnO} / \mathrm{Cu}$ sample, the Al-modified material being more active than the S-modified one. This is not surprising because sulfur is known to be an effective poison for copper-based catalysts. The activity of the superior Al@ZnO/Cu material was investigated in more detail and was compared with that of the industrial $\mathrm{Cu} / \mathrm{ZnO} / \mathrm{Al}_{2} \mathrm{O}_{3}$ reference catalyst tested under the same conditions. For such comparison, the reaction rate may be related to different quantities: to the exposed $\mathrm{Cu}$ surface area, which describes the intrinsic activity of the $\mathrm{Cu}$ surface sites under the promoting action of the zinc, or to the catalyst mass, which indicates the actual productivity in practical application. The $\mathrm{Cu}$ surface areas were found to be $23.8 \mathrm{~m}^{2}$ and $0.8 \mathrm{~m}^{2} \mathrm{~g}^{-1}$ catalyst for the industrial reference and our $\mathrm{Al} @ \mathrm{ZnO} / \mathrm{Cu}$ material, respectively. The very low $\mathrm{Cu}$ surface area of our sample is partly due to the relatively large size of the $\mathrm{Cu}$ particles, in addition, significant parts of the particle surface appear to be shielded from the gas phase by contact with the pore walls. This shows the need for further optimization of our material, which is, however, beyond the scope of the present work. With these data, the intrinsic activity was $945 \mu \mathrm{mol} \mathrm{h}{ }^{-1}$ $\mathrm{m}_{\mathrm{Cu}}{ }^{-2}$ for the Al@ZnO/Cu sample and $179 \mu \mathrm{mol} \mathrm{h}^{-1} \mathrm{~m}_{\mathrm{Cu}}{ }^{-2}$ for the industrial reference. Apparently, the surface copper sites in our catalyst were on average five times as active as those in the industrial sample. This may be related to the presence of $\mathrm{Al}$ in the zinc oxide: it has been reported recently that the defects introduced into $\mathrm{ZnO}$ by the $\mathrm{Al}^{3+}$ ions appear to intensify the SMSI behavior of the zinc oxide, ${ }^{\mathbf{8 0}, 81}$ which may be considered as an indirect electronic promotion. For practical purposes, the mass-related activity is, of course, more important. Not unexpectedly, this comparison is in favor of the industrial reference $\left(4274 \mu \mathrm{mol} \mathrm{h}^{-1} \mathrm{~g}_{\text {Kat }}{ }^{-1}\right.$ vs. $\left.756 \mu \mathrm{mol} \mathrm{h}^{-1} \mathrm{~g}_{\text {Kat }}{ }^{-1}\right)$. The difference is, however, moderate and may well be equalized by a further optimization of our synthesis procedures, in particular regarding the exposed $\mathrm{Cu}$ surface area.

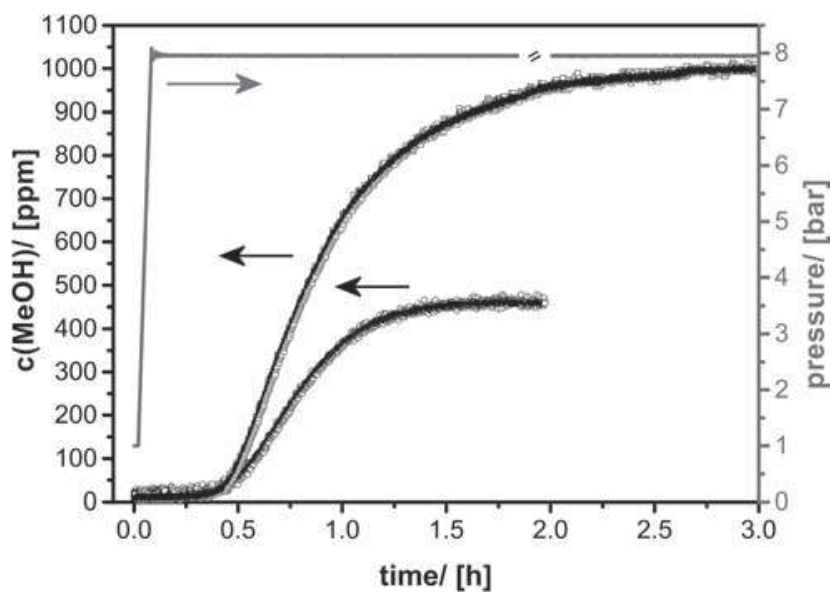

Fig. 7 Catalytic testing of Al@ZnO/Cu (squares) and $\mathrm{S} a \mathrm{ZnO} / \mathrm{Cu}$ (circles) nanocomposites. Reaction conditions: $493 \mathrm{~K}, 8$ bar, synthesis gas composition: $10 \% \mathrm{CO}, 4 \% \mathrm{CO}_{2}, 14 \% \mathrm{He}, 72 \% \mathrm{H}_{2}$. 


\section{Conclusion}

A new method for the synthesis of porous metal oxides is presented. The influence of impurities on crystallinity, porosity and stability towards thermal treatment is investigated. Nanosized $\mathrm{ZnO}$ spheres were synthesized from the organometallic precursor [MeZnOEtOMe $]_{4}$ via an aerosol assisted technique. By adding non-ionic surfactants and amphiphilic block-copolymers as structure directing agents to the precursor solution, hierarchically structured spheres with significant porosity were obtained. $\left[\mathrm{MeZnS}{ }^{\text {iso }} \mathrm{Pr}\right]_{8}$ or $\mathrm{Al}\left(\mathrm{O}^{\text {iso }} \mathrm{Pr}\right)_{3}$ were added as impurity sources to the precursor solution in order to introduce the elements $\mathrm{E}=\mathrm{S}$ or $\mathrm{Al}$ to the $\mathrm{ZnO}$ matrix. It turns out that the presence of impurity atoms has a strong influence on crystallinity. Since the impurity doped $\mathrm{ZnO}$ spheres are constructed of very small crystallites, they exhibit larger specific surface areas than the undoped ones. It was demonstrated that the presence of impurities can improve the overall stability toward sintering during thermal treatment. While the crystallites of doped $\mathrm{ZnO}$ grow dramatically during annealing to $500{ }^{\circ} \mathrm{C}$, the change in crystallite size of the E@ZnO spheres remains negligible. As a result, morphology and porosity can be preserved. Since thermal instability poses a big problem in many applications, this knowledge can help to generate nanostructures with enhanced performance, for example in heterogeneous catalysis.

The hierarchically structured mesoporous spheres are well suited for heavy metal adsorption in environmental remediation. It was shown that these spheres exhibit excellent adsorption capacities towards $\mathrm{Cu}^{\mathrm{II}}$ ions in solution. Furthermore we demonstrate that $\mathrm{Cu}^{\mathrm{II}}$ adsorption can be utilized to synthesize complex structured nanocomposites. By adsorbing a specific amount of $\mathrm{Cu}^{\mathrm{II}}$, the mesoporous E@ZnO spheres were converted into a porous heterogeneous catalyst which was tested successfully in methanol synthesis.

\section{Materials and methods}

All starting compounds were received from Aldrich, purified and carefully dried prior to use. All reactions were performed under strict exclusion of air and humidity using the Schlenk technique. The substances $[\mathrm{MeZnOEtOMe}]_{4}$ and $[\mathrm{MeZnS-i-Pr}]_{8}$ were synthesized according to methods reported in the literature. ${ }^{51,61} \mathrm{Al}(\mathrm{O}-\mathrm{i}-\mathrm{Pr})_{3}$ was purchased from Sigma Aldrich and dried under vacuum.

\section{Precursor solution for synthesis of mesoporous $\mathrm{ZnO}$ spheres}

The precursor solution was prepared by dissolving $0.8 \mathrm{~g}$ (1.286 $\left.\times 10^{-3} \mathrm{~mol}\right)$ of $[\mathrm{MeZnOEtOMe}]_{4}$ and $0.181 \mathrm{~g}\left(1.608 \times 10^{-4} \mathrm{~mol}\right)$ of Brij 58 in $12.9 \mathrm{ml}$ of dried toluene.

\section{Precursor solution for synthesis of mesoporous S@Zno spheres}

The precursor solution was prepared by dissolving $0.8 \mathrm{~g}$ $\left(1.286 \times 10^{-3} \mathrm{~mol}\right)$ of $[\mathrm{MeZnOEtOMe}]_{4}, 0.12 \mathrm{~g}(9.646 \times$ $\left.10^{-5} \mathrm{~mol}\right)$ of $[\mathrm{MeZnS}-\mathrm{i}-\mathrm{Pr}]_{8}$ and $0.194 \mathrm{~g}\left(1.728 \times 10^{-4} \mathrm{~mol}\right)$ of Brij 58 in $13.8 \mathrm{ml}$ of dried toluene.

\section{Precursor solution for synthesis of mesoporous Al@ZnO} spheres

A precursor solution was prepared by dissolving $0.8 \mathrm{~g}(1.286 \times$ $\left.10^{-3} \mathrm{~mol}\right)$ of $[\mathrm{MeZnOEtOMe}]_{4}, 0.079 \mathrm{~g}\left(3.859 \times 10^{-4} \mathrm{~mol}\right)$ of $\mathrm{Al}(\mathrm{O}-\mathrm{i}-\mathrm{Pr})_{3}$ and $0.235 \mathrm{~g}\left(2.090 \times 10^{-4} \mathrm{~mol}\right)$ of Brij 58 in $16.7 \mathrm{ml}$ of dried toluene.

\section{Aerosol assisted synthesis of mesoporous (E)@ZnO spheres}

The precursor solution was injected into the gas-phase reactor which consists of an atomizer (Constant Output Atomizer, Model 3076, TSI), an evaporation zone (tube oven 1, Nabertherm, set to $150^{\circ} \mathrm{C}$ ) and a heating zone (tube oven 2, Nabertherm, set to $350^{\circ} \mathrm{C}$ ). After atomization, the aerosol was passed into the evaporation zone with a constant nitrogen flow of $1.31 \mathrm{~min}^{-1}$. Prior to the heating zone, oxygen was additionally introduced with a constant flow rate of $0.5 \mathrm{l} \mathrm{min}^{-1}$. After the heating zone, the solid spheres were deposited on paper filters. The product was isolated and annealed for $15 \mathrm{~h}$ at $300{ }^{\circ} \mathrm{C}$.

\section{$\mathrm{Cu}^{(\mathrm{II})}$ adsorption experiments}

$10 \mathrm{mg}$ of the mesoporous (E)@ZnO spheres were dispersed in $10 \mathrm{ml}$ of an aqueous $\mathrm{Cu}\left(\mathrm{NO}_{3}\right)_{2}$ solution $(2000 \mathrm{ppm})$. After 5 hours, the spheres were separated by centrifugation. The $\mathrm{Cu}(\mathrm{II})$ content in the remaining filtrate was determined via AAS (Atom Adsorption Spectroscopy).

\section{Synthesis of $\mathrm{Cu}^{(\mathrm{II})}$ containing mesoporous S@ZnO nanocomposite}

$40 \mathrm{mg}$ of the mesoporous S@ZnO spheres were dispersed in 40 $\mathrm{ml}$ of a NaOH-glucose solution $(0.1 \mathrm{M} / 0.2 \mathrm{M}) \cdot 15.7 \mathrm{ml}$ of a $\mathrm{Cu}\left(\mathrm{NO}_{3}\right)_{2}$ solution $\left(7.85 \mathrm{mM}\right.$ in $\left.\mathrm{H}_{2} \mathrm{O}\right)$ was added drop by drop. The suspension was stirred for 2 hours and the spheres were separated by centrifugation and washed three times with $\mathrm{H}_{2} \mathrm{O}$. After drying, the product was annealed for 10 hours at $300{ }^{\circ} \mathrm{C}$.

\section{Synthesis of $\mathrm{Cu}^{(\mathrm{II})}$ containing mesoporous Al@ZnO nanocomposite}

$40 \mathrm{mg}$ of the mesoporous Al@ZnO spheres were dispersed in $40 \mathrm{ml}$ of a $\mathrm{NaOH} /$ glucose solution $(0.1 \mathrm{M} / 0.2 \mathrm{M}) .16 .5 \mathrm{ml}$ of a $\mathrm{Cu}\left(\mathrm{NO}_{3}\right)_{2}$ solution $\left(7.85 \mathrm{mM}\right.$ in $\left.\mathrm{H}_{2} \mathrm{O}\right)$ was added drop by drop. The spheres were isolated and treated as reported before.

\section{Methanol synthesis}

$50 \mathrm{mg}$ of the catalyst (sieve fraction $250-355 \mu \mathrm{m}$ ) were placed into a fixed-bed glass-lined U-tube reactor. Reduction of the catalyst was carried out in diluted $\mathrm{H}_{2}\left(2 \% \mathrm{H}_{2}\right.$ in $\left.\mathrm{He}\right)$, ramping the temperature from room temperature to $513 \mathrm{~K}\left(2 \mathrm{~K} \mathrm{~min}^{-1}\right)$. The methanol synthesis activity was measured at 8 bar and 493 $\mathrm{K}$. The synthesis gas was composed of $72 \% \mathrm{H}_{2}, 10 \% \mathrm{CO}, 4 \% \mathrm{CO}_{2}$ and $14 \% \mathrm{He}$ (with the highest purity of $>99.9995 \%$ ). A weightfeed ratio of $0.21 \mathrm{~g} \mathrm{~s} \mathrm{ml}^{-1}$ was chosen. The gas phase was analyzed with a detector based on non-dispersive IR photometry (Emerson XStream2GP). Additionally, an industrial reference catalyst $\left(\mathrm{Cu} / \mathrm{ZnO} / \mathrm{Al}_{2} \mathrm{O}_{3}\right)$ was tested under the same conditions. 
The specific copper surface area was determined after standard reduction in diluted hydrogen via $\mathrm{N}_{2} \mathrm{O}$ reactive frontal chromatography. ${ }^{82}$

\section{Analytical techniques}

NMR-spectra were acquired on a Varian Unity INOVA 400 spectrometer. X-Ray diffraction was performed on a Bruker AXS D8 Advance diffractometer using $\mathrm{Cu} \mathrm{K} \alpha$ radiation. The UV/Vis measurements were done on a Varian Cary 100 scan UV/Vis spectrophotometer equipped with an Ulbricht reflecting sphere. TEM images were acquired on a Zeiss Libra 120 at $120 \mathrm{kV}$ acceleration voltage and STEM images on a JEOL JEM 2200FS. SEM images were acquired on a Zeiss Crossbeam IS40XB instrument. EDX-maps and line-scan EDX data were acquired on a JEOL JEM 2200FS equipped with an EDX detector. TGA was performed on equipment from Netzsch. $\mathrm{N}_{2}$ physisorption measurements were performed on a Micromeritics Tristar. ${ }^{27} \mathrm{Al}$ solid-state NMR spectra were performed on a Bruker DRX 400 spectrometer with a one pulse experiment. XPS measurements were performed on equipment with a dual anode $\mathrm{Al} / \mathrm{Mg} \mathrm{K} \alpha \mathrm{X}$-ray source from VG Microtech and a cylindrical hemispherical analyzer from Omicron (EA 125). The $\mathrm{Mg} \mathrm{K} \alpha$ (photon energy $1253.6 \mathrm{eV}$ ) was used for measurement.

\section{Acknowledgements}

This work was funded by the Carl-Zeiss foundation within the REFINE project.

\section{Notes and references}

1 M. Anpo and M. Takeuchi, J. Catal., 2003, 216, 505-516.

2 M. R. Hoffmann, S. T. Martin, W. Y. Choi and D. W. Bahnemann, Chem. Rev., 1995, 95, 69-96.

3 M. Vallet-Regi, F. Balas and D. Arcos, Angew. Chem., Int. Ed., 2007, 46, 7548-7558.

4 R. Schloegl and S. B. Abd Hamid, Angew. Chem., Int. Ed., 2004, 43, 1628-1637.

5 K. C. Waugh, Catal. Today, 1992, 15, 51-75.

6 T. Ressler, B. L. Kniep, I. Kasatkin and R. Schloegl, Angew. Chem., Int. Ed., 2005, 44, 4704-4707.

7 A. S. Arico, P. Bruce, B. Scrosati, J. M. Tarascon and W. Van Schalkwijk, Nat. Mater., 2005, 4, 366-377.

8 K. M. McGrath, G. K. S. Prakash and G. A. Olah, J. Ind. Eng. Chem., 2004, 10, 1063-1080.

9 S. Wasmus and A. Kuver, J. Electroanal. Chem., 1999, 461, 1431.

10 M. Behrens, J. Catal., 2009, 267, 24-29.

11 M. Behrens, F. Studt, I. Kasatkin, S. Kuhl, M. Havecker, F. Abild-Pedersen, S. Zander, F. Girgsdies, P. Kurr, B. L. Kniep, M. Tovar, R. W. Fischer, J. K. Norskov and R. Schloegl, Science, 2012, 336, 893-897.

12 M. Kurtz, H. Wilmer, T. Genger, O. Hinrichsen and M. Muhler, Catal. Lett., 2003, 86, 77-80.

13 S. J. Tauster, Acc. Chem. Res., 1987, 20, 389-394.
14 S. Polarz, F. Neues, M. W. E. van den Berg, W. Gruenert and L. Khodeir, J. Am. Chem. Soc., 2005, 127, 12028-12034.

15 G. Y. Wang, W. X. Zhang, H. L. Lian, D. Z. Jiang and T. H. Wu, Appl. Catal., A, 2003, 239, 1-10.

16 X. H. Liu, J. Zhang, L. W. Wang, T. L. Yang, X. Z. Guo, S. H. Wu and S. R. Wang, J. Mater. Chem., 2011, 21, 349-356.

17 Y. H. Zheng, L. R. Zheng, Y. Y. Zhan, X. Y. Lin, Q. Zheng and K. M. Wei, Inorg. Chem., 2007, 46, 6980-6986.

18 U. Ozgur, Y. I. Alivov, C. Liu, A. Teke, M. A. Reshchikov, S. Dogan, V. Avrutin, S. J. Cho and H. Morkoc, J. Appl. Phys., 2005, 98, 041301.

19 C. Klingshirn, Phys. Status Solidi B, 2007, 244, 3027-3073.

20 G. D. Mahan, L. M. Levinson and H. R. Philipp, J. Appl. Phys., 1979, 50, 2799-2812.

21 Y. S. Choi, J. W. Kang, D. K. Hwang and S. J. Park, IEEE Trans. Electron Devices, 2010, 57, 26-41.

22 R. L. Hoffman, B. J. Norris and J. F. Wager, Appl. Phys. Lett., 2003, 82, 733-735.

23 Q. Wan, Q. H. Li, Y. J. Chen, T. H. Wang, X. L. He, J. P. Li and C. L. Lin, Appl. Phys. Lett., 2004, 84, 3654-3656.

24 S. Polarz, A. Roy, M. Lehmann, M. Driess, F. E. Kruis, A. Hoffmann and P. Zimmer, Adv. Funct. Mater., 2007, 17, 1385-1391.

25 S. Dilger, C. Lizandara-Pueyo, M. Krumm and S. Polarz, Adv. Mater., 2012, 24, 543.

26 E. Selli, A. DeGiorgi and G. Bidoglio, Environ. Sci. Technol., 1996, 30, 598-604.

27 L. B. Khalil, W. E. Mourad and M. W. Rophael, Appl. Catal., $B, 1998,17,267-273$.

28 X. W. Zhao and L. M. Qi, Nanotechnology, 2012, 23, 235604.

29 X. B. Wang, W. P. Cai, Y. X. Lin, G. Z. Wang and C. H. Liang, J. Mater. Chem., 2010, 20, 8582-8590.

30 X. F. Ma, Y. Q. Wang, M. J. Gao, H. Z. Xu and G. A. Li, Catal. Today, 2010, 158, 459-463.

31 Z. L. Wang, J. Phys.: Condens. Matter, 2004, 16, R829-R858.

32 S. Polarz, C. L. Pueyo and M. Krumm, Inorg. Chim. Acta, 2010, 363, 4148-4157.

33 M. M. Khin, A. S. Nair, V. J. Babu, R. Murugan and S. Ramakrishna, Energy Environ. Sci., 2012, 5, 8075-8109.

34 L. Li, C. K. Tsung, Z. Yang, G. D. Stucky, L. D. Sun, J. F. Wang and C. H. Yan, Adv. Mater., 2008, 20, 903-908.

35 Z. Jin, M. Xiao, Z. Bao, P. Wang and J. Wang, Angew. Chem., Int. Ed., 2012, 51, 6406-6410.

36 Z. Jin, F. Wang, F. Wang, J. Wang, J. C. Yu and J. Wang, Adv. Funct. Mater., 2013, 23, 2137-2144.

37 T. P. Chou, Q. F. Zhang, G. E. Fryxell and G. Z. Cao, Adv. Mater., 2007, 19, 2588-2592.

38 Q. F. Zhang, T. R. Chou, B. Russo, S. A. Jenekhe and G. Z. Cao, Angew. Chem., Int. Ed., 2008, 47, 2402-2406.

39 H. J. Zhang, R. F. Wu, Z. W. Chen, G. Liu, Z. N. Zhang and Z. Jiao, CrystEngComm, 2012, 14, 1775-1782.

40 F. Xu, P. Zhang, A. Navrotsky, Z. Y. Yuan, T. Z. Ren, M. Halasa and B. L. Su, Chem. Mater., 2007, 19, 5680-5686.

41 G. K. Zhang, X. O. Shen and Y. Q. Yang, J. Phys. Chem. C, 2011, 115, 7145-7152.

42 S. Polarz and S. Dilger, in BioInorg. Reac. Mech., 2011, vol. 7, p. 27. 
$43 \mathrm{H}$. von Wenckstern, H. Schmidt, M. Brandt, A. Lajn, R. Pickenhain, M. Lorenz, M. Grundmann, D. M. Hofmann, A. Polity, B. K. Meyer, H. Saal, M. Binnewies, A. Borger, K. D. Becker, V. A. Tikhomirov and K. Jug, Prog. Solid State Chem., 2009, 37, 153-172.

44 A. Sanchez-Juarez, A. Tiburcio-Silver and A. Ortiz, Sol. Energy Mater. Sol. Cells, 1998, 52, 301-311.

45 H. Y. Xu, Y. C. Liu, R. Mu, C. L. Shao, Y. M. Lu, D. Z. Shen and X. W. Fan, Appl. Phys. Lett., 2005, 86, 123107.

46 D. H. Zhang, T. L. Yang, J. Ma, Q. P. Wang, R. W. Gao and H. L. Ma, Appl. Surf. Sci., 2000, 158, 43-48.

47 J. Lee, D. Lee, D. Lim and K. Yang, Thin Solid Films, 2007, 515, 6094-6098.

48 T. Minami, Thin Solid Films, 2008, 516, 1314-1321.

49 T. Makino, Y. Segawa, M. Kawasaki, A. Ohtomo, R. Shiroki, K. Tamura, T. Yasuda and H. Koinuma, Appl. Phys. Lett., 2001, 78, 1237-1239.

50 B. K. Meyer, A. Polity, B. Farangis, Y. He, D. Hasselkamp, T. Kramer and C. Wang, Appl. Phys. Lett., 2004, 85, 49294931.

51 D. Lehr, M. Luka, M. R. Wagner, M. Bulger, A. Hoffmann and S. Polarz, Chem. Mater., 2012, 24, 1771-1778.

52 P. J. Gellings and H. J. M. Bouwmeester, Catal. Today, 1992, 12, 1-105.

53 M. W. E. van den Berg, S. Polarz, O. Tkachenko, K. Kahler, M. Muhler and W. Gruenert, Catal. Lett., 2009, 128, 49-56.

54 M. W. E. van den Berg, S. Polarz, O. P. Tkachenko, K. V. Klementiev, M. Bandyopadhyay, L. Khodeir, H. Gies, M. Muhler and W. Gruenert, J. Catal., 2006, 241, 446-455.

55 C. J. Brinker, Y. F. Lu, A. Sellinger and H. Y. Fan, Adv. Mater., 1999, 11, 579.

56 Y. F. Lu, H. Y. Fan, A. Stump, T. L. Ward, T. Rieker and C. J. Brinker, Nature, 1999, 398, 223-226.

57 M. Krumm, F. Pawlitzek, J. Weickert, L. Schmidt-Mende and S. Polarz, ACS Appl. Mater. Interfaces, 2012, 4, 65226529.

58 C. Lizandara-Pueyo, S. Siroky, M. R. Wagner, A. Hoffmann, J. S. Reparaz, M. Lehmann and S. Polarz, Adv. Funct. Mater., 2011, 21, 295-304.

59 C. L. Pueyo, S. Siroky, S. Landsmann, M. W. E. van den Berg, M. R. Wagner, J. S. Reparaz, A. Hoffmann and S. Polarz, Chem. Mater., 2010, 22, 4263-4270.

60 M. Krumm, C. L. Pueyo and S. Polarz, Chem. Mater., 2010, 22, 5129-5136.

61 C. Lizandara-Pueyo, M. W. E. van den Berg, A. De Toni, T. Goes and S. Polarz, J. Am. Chem. Soc., 2008, 130, 1660116610 .
62 S. Polarz, A. V. Orlov, F. Schueth and A. H. Lu, Chem.-Eur. J., 2007, 13, 592-597.

63 S. Polarz, J. Strunk, V. Ischenko, M. W. E. van den Berg, O. Hinrichsen, M. Muhler and M. Driess, Angew. Chem., Int. Ed., 2006, 45, 2965-2969.

64 S. Polarz, A. Roy, M. Merz, S. Halm, D. Schroder, L. Schneider, G. Bacher, F. E. Kruis and M. Driess, Small, 2005, 1, 540-552.

65 V. Ischenko, S. Polarz, D. Grote, V. Stavarache, K. Fink and M. Driess, Adv. Funct. Mater., 2005, 15, 1945-1954.

66 D. Schroeder, H. Schwarz, S. Polarz and M. Driess, Phys. Chem. Chem. Phys., 2005, 7, 1049-1053.

67 C. Lizandara-Pueyo, M. C. Morant-Minana, M. Wessig, M. Krumm, S. Mecking and S. Polarz, RSC Adv., 2012, 2, 5298-5306.

68 S. Polarz and B. Smarsly, J. Nanosci. Nanotechnol., 2002, 2, 581-612.

69 B. Smarsly, S. Polarz and M. Antonietti, J. Phys. Chem. B, 2001, 105, 10473-10483.

70 S. J. Gregg and K. S. W. Sing, Adsorption, Surface Area and Porosity, Academic Press, Oxford, 4th edn, 1982.

71 E. P. Barret, L. G. Joyner and P. H. Halenda, J. Am. Chem. Soc., 1951, 73, 373-380.

72 S. Brunauer, P. H. Emmet and E. Teller, J. Am. Chem. Soc., 1938, 60, 309.

73 S. Polarz, R. Regenspurger and J. Hartmann, Angew. Chem., Int. Ed., 2007, 46, 2426-2430.

74 A. Gunier, X-Ray Diffraction in Crystals, Imperfect Crystals, and Amorphous Bodies, Dover Publ., Toronto, 1994.

75 F. T. J. Smith, Appl. Phys. Lett., 1983, 43, 1108-1110.

76 Y. S. Avadhut, J. Weber, E. Hammarberg, C. Feldmann and J. S. a. d. Guenne, Phys. Chem. Chem. Phys., 2012, 14, 11610-11625.

77 K. Awazu and H. Kawazoe, J. Appl. Phys., 2003, 94, 6243-6262.

78 S. Y. Kuo, W. C. Chen, F. I. Lai, C. P. Cheng, H. C. Kuo, S. C. Wang and W. F. Hsieh, J. Cryst. Growth, 2006, 287, 78-84.

79 K. C. Barick, M. Aslam, V. P. Dravid and D. Bahadur, J. Phys. Chem. C, 2008, 112, 15163-15170.

80 M. Behrens, S. Zander, P. Kurr, N. Jacobsen, J. Senker, G. Koch, T. Ressler, R. W. Fischer and R. Schloegl, J. Am. Chem. Soc., 2013, 135, 6061-6068.

81 S. J. Miao, R. N. d'Alnoncourt, T. Reinecke, I. Kasatkin, M. Behrens, R. Schloegl and M. Muhler, Eur. J. Inorg. Chem., 2009, 910-921.

82 G. C. Chinchen, C. M. Hay, H. D. Vandervell and K. C. Waugh, J. Catal., 1987, 103, 79-86. 